\title{
RELAÇÕES DE GÊNERO E A MÚSICA POPULAR BRASILEIRA: UM ESTUDO SOBRE AS BANDAS FEMININAS. ${ }^{1}$
}

\author{
Rodrigo Cantos Savelli Gomes², Maria Ignez Cruz Mello³.
}

PALAVRAS-CHAVE: relações de gênero e música; bandas femininas; etnomusicologia.

RESUMO: Esta comunicação trata da temática das relações de gênero na música popular brasileira a partir da perspectiva etnomusicológica, investigando a participação das mulheres em grupos de música popular, especialmente no rock, samba, pagode e hip-hop. Através de relatos, observações e pesquisa em diferentes mídias, procuramos apontar para os diversos espaços que vêm sendo ocupados atualmente por estes grupos femininos, bem como para os diálogos que vêm sendo estabelecidos entre eles, e de que forma a organização dos mesmos tem possibilitado a contestação e a transformação dos papéis de gênero vigentes.

Esta investigação tem como objetivo refletir sobre como as relações de gênero, instituídas de poder, prestígio, hierarquia e discriminações, afetam, modelam e estruturam o discurso e a performance ${ }^{4}$ musical das integrantes das bandas femininas da região da Grande Florianópolis, Santa Catarina. Pretende-se, assim, discutir em que medida a produção e o discurso musical das integrantes destas bandas revelam questões relacionadas à temática de gênero, seja através da organização social no momento da performance musical, seja através das letras das canções, das narrativas recolhidas através de entrevistas e depoimentos, bem como dos processos composicionais empregados pelas musicistas.

Sendo a música uma das manifestações culturais mais próximas do cotidiano das pessoas, esta pesquisa parte do princípio que a mesma pode estar diretamente afetada por essas determinações (BRETT e WOOD, 2002) ${ }^{5}$, seja reproduzindo, afirmando ou contestando modelos e costumes vigentes.

Apesar do grande avanço, nas diferentes áreas do conhecimento, em estudos sobre as relações de gênero, alguns setores da sociedade ainda não exploraram o tema em seus mais variados aspectos, como é o caso dos estudos sobre a produção musical feminina.

\footnotetext{
${ }^{1}$ Projeto de Pesquisa CEART/UDESC.

2 Acadêmico do curso de Licenciatura em Música CEART/UDESC e Bolsista de Iniciação Científica do PROBIC/UDESC.

${ }^{3}$ Orientadora, Professora do Departamento de Música CEART/UDESC - Av. Madre Benvenuta, 1907, CEP 99.035001 Florianópolis - SC.Tel.: (048) 3231-9747.

${ }^{4}$ Assim como Small (1989), referimo-nos a "performance" não como aquela ligada às habilidades técnicas, físicomotoras, mas sim ao evento social onde uns tocam e outros ouvem, onde a experiência do fazer e da interação entre as pessoas é mais relevante do que o produto final.

${ }^{5} \mathrm{O}$ artigo de Brett e Wood (2002) - traduzido e comentado por Carlos Palombini, professor adjunto de Musicologia da Escola de Música da UFMG - revela como e porque discussões relacionadas à diversidade sexual (homossexualismo, bissexualismo, transsexualismo, etc), assim como as temáticas de gênero, foram mantidas à margem dos debates pela musicologia moderna positivista. Segundo os autores, questões como homossexualismo e gênero desviam o aspecto da "música centrada em si" - fenômeno da "música absoluta" - representando uma ameaça à hegemonia viril, ao status da ciência marcada pela lógica do raciocínio, pelo culto ao intelecto, pela demonstração de força e seriedade, na tentativa de manter-se como fonte absoluta de verdade e poder. Deste modo, a música afastou-se dos elementos básicos da vida comum, do cotidiano das pessoas, centrando-se em aspectos essencialmente técnicos e racionais.
}

DAPesquisa, Florianópolis, v.2, n.4, p. 500 - 510, 2007. 
No Brasil ${ }^{6}$, as grandes temáticas que permeiam as discussões em torno da categoria de gênero têm pouca repercussão nos estudos sobre música, sendo abordado, na maior parte das vezes, as questões que dizem respeito ao trabalho, violência e sexualidade.

Os estudos que envolvem a questão de gênero na música brasileira apontam predominantemente para a análise do discurso embutido nas letras das canções, onde se coloca em evidência a representação feminina, os estereótipos e a imagem da mulher narrada pelos cancioneiros em seus versos.

Estes estudos são, na sua maioria, dirigidos por áreas do conhecimento alheias à musicologia, como é o caso dos estudos em Letras e Literatura (BELTRÃO, 1993; SANTA CRUZ, 1992; BARBOSA, M., 2005), Ciências Sociais e Ciências Políticas (COSTA, 2006; BARBOSA, V., 2006), História e História Social (FARIA, 2002; ERTZOGUE, 2002, VEIGA 2006; MATOS, 2004).

Outra vertente tem se dedicado a identificar onde estão as mulheres no meio musical, que funções exercem e qual a importância delas no contexto social da sua época. Nesta linha também se destacam os estudos biográficos de mulheres que tiveram significativa repercussão nos ambientes artístico-musicais de sua época (STIVAL, 2004; BARONCELLI, 1987; CHAVES, 2006; SARTORI, 2006; MEDIA, 2006; PACHECO e KAYAMA, 2006; WELLER, 2005; DINIZ, 1984; KATER, 2001; LIRA, 1978; SCARINCI, 2006).

A antropologia tem dado certo destaque a esta discussão, ao olhar para a questão de gênero e música a partir de outras culturas, principalmente as indígenas, como é o caso dos estudos em Etnomusicologia que vêm sendo realizados nas aldeias indígenas brasileiras (MELLO, 2005; PIEDADE 2004; BASTOS, 1999).

$\mathrm{Na}$ Musicologia, Holanda (2006) trás em sua tese ${ }^{7}$ uma importante discussão sobre a questão de gênero na linguagem musical, acompanhada no campo da Educação Musical por Helena Lopez

\footnotetext{
${ }^{6}$ Holanda e Gerling (2005) e Mello (2006) revelam que pesquisas sobre música e gênero tiveram maior abrangência em países como EUA e Inglaterra, sendo estes considerados os precursores na abordagem deste assunto. Segundo as autoras, os primeiros vestígios começaram por volta anos 80 nos Estados Unidos, com as primeiras antologias de partituras e biografias de compositoras. Nos anos 90 Susan McClary (1991), Lawrence Krammer (1990) e Marcia Citron (1993), levantaram os primeiros debates sobre as metáforas de gênero no código musical, mostrando como convenções e construções retóricas da teoria e análise musical podem estar repletas de metáforas sexuais construídas a partir de sensações e impressões que refletem majoritariamente o modelo de masculinidade. Ainda na década de 90, outras autoras como Ellen Walterman (1993), Suzanne G. Cusick (1994) e também as já citadas Marcia Citron (1993) e Susan McClary (1991) procuraram perceber pontos diferenciais nas estruturas e elaborações de composições, arranjos e interpretações em atividades femininas, a fim de revelar como as mulheres encontram mecanismos para expressar sua subjetividade em um sistema musical construído sobre o domínio patriarcal.

${ }^{7}$ Joana Holanda (2006) conduz uma investigação sobre a música de Eunice Katunda e Esther Scliar, a partir de suas trajetórias individuais e pela análise musical das obras Sonata Louvação e Sonata para Piano das respectivas compositoras. Esta pesquisa é um importante referencial sobre os estudos de gênero em música, visto que "esta questão é problematizada tanto no estudo do texto musical [análise], a partir do referencial teórico de estudos de gênero em música, [mais especificamente focalizando código e conceitos musicais], quando na abordagem de suas trajetórias" individuais (p. 19); onde a questão é problematizada a partir do contexto sócio-cultural; do engajamento das compositoras em diversos movimentos como o grupo 'música viva', o nacionalismo, o partido comunista (PCB); e também pela sua intransferível identidade social, como sujeito 'mulheres'.
}

DAPesquisa, Florianópolis, v.2, n.4, p. 500 - 510, 2007. 
da Silva (2000) que conduz proveitosas reflexões em relação à construção da identidade de gênero na adolescência a partir dos usos simbólicos da música no espaço escolar.

Desse modo, este trabalho procura fomentar o debate sobre a temática de gênero a partir da perspectiva (etno)musicológica. Para tanto, desde o início desta investigação vem-se realizando uma sondagem - tanto a nível regional como nacional - a fim de identificar a presença das mulheres nos grupos de música popular brasileira. Num primeiro momento, o trabalho consistiu em uma sondagem sobre quais são os grupos femininos, quem e quantas são as integrantes, onde moram, onde e para que tipo de público se apresentam, que instrumentos e estilos de música tocam ou cantam. Indiscutivelmente, um dado que veio à tona logo nas primeiras buscas é que a quantidade de grupos formados exclusivamente por homens supera exorbitantemente o número de grupos musicais femininos.

Algumas bandas com ideologias e/ou atitudes feministas se destacaram por expressar em suas letras o desejo pela igualdade entre os sexos, a quebra do preconceito racial e sexual ou, simplesmente, por se autodeclararem feministas em seus depoimentos e entrevistas. Curiosamente, todas as bandas encontradas classificam-se dentro do gênero rock, o que evidencia a preferência das mulheres ativistas por este gênero musical. Entre as investigadas ressaltaram-se as bandas Bulimia (Brasília/DF), Close (Olinda/PE), NoDolls (Goiânia/GO), Cosmogonia (São Paulo/SP), Dominatrix (São Paulo/SP), S.A.44 (São Paulo/SP), The Hats (São Paulo/SP), Female (Belo Horizonte/MG), Afasia (Uberlândia/MG), Insana Z (Ponta Grossa/PR).

Algumas se distinguiram por explorar através do nome do grupo a combinação excêntrica de seus integrantes, como, por exemplo, a banda de pop/rock Elas e Eu (São Paulo/SP) e o grupo de Mpb Ele por Elas (Rio de Janeiro/RJ), que identificam a sexualidade de seus membros através do nome escolhido para seu conjunto musical.

Outras bandas formadas por mulheres também fazem questão de identificar esse diferencial na sua identidade, apresentando-se como "banda estritamente feminina", ou "banda só de garotas" como é o caso dos grupos de rock Lazy Moon (Cuiabá/MT), Punkake (Curitiba/PR), RNA (Serra/ES), Ladies Die (João Pessoa/PA), Veno (Rio de Janeiro/RJ), e a banda Jaspe (São Paulo/SP) na linha gospel.

Em Florianópolis, foram encontrados cinco grupos musicais formados apenas por mulheres. Devido à aproximação territorial, com estas bandas foi possível realizarmos uma pesquisa mais circunstanciada $^{8}$, pudemos assistir suas apresentações, registrá-las em diários de campo, áudio, fotografia e filmagens, bem como realizar entrevistas e conversas com algumas de suas integrantes.

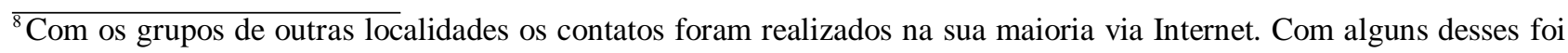
possível uma aproximação maior através do envio de um questionário via e-mail, como por exemplo, as bandas $S . A .44$, RNA, Give Me a Break, Lazy Moon, Blush Azul e o grupo Elas e Eu.
}

DAPesquisa, Florianópolis, v.2, n.4, p. 500 - 510, 2007. 
Por esta razão, foram tomadas como centro principal para a discussão deste trabalho os seguintes grupos:

Entre Elas. Com oito garotas e uma empresária, este conjunto de pagode vem se destacando a cerca de um ano na região, realizando diversos shows em bares e casas noturnas, apresentando-se nos principais eventos da cidade e do estado, participando, eventualmente, em programas de rádio e televisão nas emissoras locais.

Declínio do Sistema. Conjunto de hip-hop formado por três mulheres, atualmente em fase de reformulação. Trabalham com composições próprias, explorando em suas letras questões relacionadas à temática feminina, preconceito sexual e racial.

Dorotéia vai à Praia. Com cinco integrantes, este grupo realizou diversas apresentações musicais pelo Estado de Santa Catarina nos últimos anos, tornando-se um dos principais representantes na cidade no gênero rock'n'roll.

Cabeça de Alface. Formado em 2003 por três garotas, desenvolvem um trabalho de composições próprias, no estilo rock alternativo, com letras baseadas na literatura "nonsense".

Carpe Diem Septem. Conjunto de rock constituído recentemente por cinco adolescentes que vem, aos poucos, realizando apresentações musicais nos bares e eventos da cidade.

Durante esta sondagem foi possível perceber que, no rock, a presença de mulheres é muito mais significativa que em outros gêneros musicais. Isso fica claro ao perceber que, das 23 bandas citadas até então, 19 se enquadram neste gênero. A mesma constatação se deu em Florianópolis, onde das cinco bandas femininas, três são adeptas do rock'n'roll ${ }^{10}$.

A preferência das mulheres pelo rock promoveu o surgimento de uma nova categoria ou subgênero, conhecido como "rock com vocal feminino" específicos para elas, como por exemplo, o Festival de Rock Feminino de Rio Claro (SP); Festival Nacional de Punk Feminino de Goiânia (GO); Festival de Música Mulheres no Volante de Juiz de Fora (MG); a criação da Rádio Feminina ${ }^{12}$ de Goiânia (GO), especializada no gênero rock'n'roll;

\footnotetext{
${ }^{9}$ Lewis Carroll, Edward Lear, Samuel Becket e James Joyce são os principais autores apontados pelas integrantes.

${ }^{10}$ Embora este artigo trate especificamente de grupos femininos, durante a pesquisa também foi atribuída uma atenção aos grupos mistos de Florianópolis, focalizando principalmente a presença de mulheres em funções culturalmente pouco atribuídas a elas, como: bateristas, baixistas, compositoras, produtoras, etc. Apesar da ampliação do foco, as circunstâncias pouco se alteraram, pois, ainda assim, a presença de mulheres foi muito mais significativa no rock do que em outros gêneros musicais. Entre os grupos mistos pesquisados podemos citar Kratera (rock), Oh Sugar! (rock), Maltines (rock), Squadrão da Rima (hip-hop), Mary Black (hip-hop), Missiva (reggae), Black Diversity (funk), Alessandra Sipriano e banda (pop/rock).

${ }^{11}$ Esta categoria surgiu primeiramente em entrevistas realizadas ao longo da pesquisa, mas verificou-se sua utilização por diferentes bandas em sites da Internet.

${ }^{12}$ A Rádio Feminina é uma iniciativa da Organização Punk Feminino que nasceu após o I Festival Nacional de punk feminino de 2006. Embora especializada no gênero rock'n'roll, ao contrário do festival, a rádio não restringe estilos, mas só toca banda com vocal feminino. Pode ser ouvida pela Internet através do endereço:

$<$ http://www.radiofeminina.cjb.net/>
}

DAPesquisa, Florianópolis, v.2, n.4, p. 500 - 510, 2007. 
bem como a criação do programa Mundo Rock de Calcinha $^{13}$ filiado à rádio Mundo Rock de São Paulo (SP).

Apesar da ampla atuação das mulheres neste gênero musical, o rock ainda é entendido como um universo masculino, conforme vários autores puderam constatar (JACQUES, 2007; WALSER, 1993; CHAVES, 2006; MEDIA, 2006; SARTORI, 2006). Segundo Jacques (2007) atribuições como potência, força, "pegada forte", resistência física e poder são características presentes no rock que são mais comumente ligadas ao ideal da masculinidade, enquanto que sensibilidade, suavidade, afetividade, são características associadas ao feminino, as quais não são bem assimiladas neste gênero musical. Por esta razão, a atuação das mulheres nem sempre foi bem vista pelos adeptos do rock, considerando a presença delas uma impureza ${ }^{14}$ (JACQUES, 2007), relacionado-as a um estilo mais comercial, subordinado ao gosto das grandes gravadoras, o que, em certa medida, pode ser usado como justificativa para a alocação em um subgênero específico para a produção feminina.

Alguns pontos serão levantados nesta discussão, enfatizando o discurso das mulheres entrevistadas ao longo da pesquisa. Nestas falas, percebemos que, embora as mulheres ainda formem a minoria no meio musical, já não há mais tanta dificuldade em se estabelecer neste espaço pelo fato de ser mulher.

"antigamente mulher pra entrar no hip-hop tinha que usar calça larga, boné, tinha que andar jogadona. A mulheres que estão entrando agora já não, tão tudo de salto, andando normal do jeito que sempre gostou, de saia curta". ${ }^{15}$

Não só o preconceito parece ser menor, como é um diferencial e um atrativo na hora da contratação pelos bares e casas noturnas.

"pelo fato de ser só mulher a gente está entrando em muitas festas pela curiosidade das pessoas". 16

"no começo, uma banda feminina é sempre super valorizada, por que não é uma coisa normal você ver uma banda com mulheres, é sempre novidade, algo que sempre atrai o público, independente

\footnotetext{
${ }^{13} \mathrm{O}$ Mundo Rock de Calcinha é um programa que toca músicas de bandas de rock e metal formadas somente por meninas ou com mulheres no vocal. Foi criado em março de 2007 por Gisele Santos, criadora também do MundoRock.net, no ar há mais de 07 anos. Pode ser ouvido através do endereço: <http://www.mundorockdecalcinha.com/>

${ }^{14}$ Vários autores utilizam a idéia de impureza a partir da observação dos discursos de vários roqueiros que enfatizam a “oposição entre a pureza da autenticidade e a impureza [da] alienação da comercialização" (JACQUES, 2007, p.84).

${ }^{15}$ Jussara Pereira Lima, vocalista do grupo de hip-hop Declínio do Sistema e coordenadora estadual da UNEGRO, entidade de âmbito nacional, fundada em Florianópolis em março de 1994, com a finalidade de contribuir para a erradicação do racismo e pelas condições de exercício dos direitos de cidadania.

${ }^{16}$ Elisa Rebelo, empresária do grupo de pagode Entre Elas.
}

DAPesquisa, Florianópolis, v.2, n.4, p. 500 - 510, 2007. 
do estilo ou qualidade. Então, é preciso aproveitar isso para mostrar o seu potencial. O problema é quando a banda se destaca e rola a conversa do tipo: “é só porque é banda só de mulher..."”. ${ }^{17}$

“poucas mulheres se expõe no meio do rock. As que o fazem, causam surpresa, claro". ${ }^{18}$

A justificativa para formar uma banda feminina aparece, em alguns casos, como uma alternativa para suprir a pouca oferta de grupos com essas características no mercado musical.

“não tem em Florianópolis um grupo só de mulheres". 19

"o grupo começou porque queriam uma banda só de mulheres pra tocar e, como não tinha nenhuma, elas montaram essa. Foi ai que a banda começou”. ${ }^{20}$

Jacques (2007) também aponta em sua investigação sobre o rock em Florianópolis para relatos de homens que dizem que as coisas seriam mais 'facilitadas' para as mulheres. "Por serem minoria, elas são tidas como diferenciais para as bandas e, para fazer parte destas, não precisariam tocar tão bem quanto os homens, pois trariam 'glamour"” (op.cit. p.99).

"a gente sabe que nosso diferencial é o fato de ser [uma banda] só mulheres, mas a gente não quer que fique só nisso, a gente quer estar nos lugares pela qualidade do nosso som, [...] não adianta ser só mulher e não tocar bem". ${ }^{21}$

Contudo, apesar do diferencial ser um atrativo, o caráter exótico traz uma certa desconfiança embutida de preconceito, tanto do público quando dos contratantes.

"Em casa noturna é assim, os caras querem que a gente toque mas falam: - ah, queria ver vocês tocar antes". ${ }^{22}$

"há receio na hora de fechar os shows. Há uma certa desconfiança de que uma banda formada por mulheres é capaz de dar conta do recado". ${ }^{23}$ “todo mundo ficava parado, esperando pra ver se realmente sabe tocar". ${ }^{24}$

\footnotetext{
${ }^{17}$ Giselle Xavier Lucena, baixista da banda de rock Blush Azul.

${ }^{18}$ Fernanda dos Santos Martins, vocalista da banda de rock S.A.44.

${ }^{19}$ Idem Nota 15.

${ }^{20}$ Juliano Silveira, baixista da banda de rock Oh, Sugar! de Florianópolis. Hoje a banda já não é mais formada exclusivamente por mulheres.

${ }^{21}$ Idem Nota 16.

${ }^{22}$ Idem Nota 16.

${ }^{23}$ Renata de Oliveira Figueiredo, baterista da banda de rock $R N A$.

${ }^{24}$ Idem Nota 16.
}

DAPesquisa, Florianópolis, v.2, n.4, p. 500 - 510, 2007. 
Quanto à peculiaridade entre homens e mulheres na execução musical, Brett e Wood (2002) levantam a questão de serem a sexualidade e o gênero audíveis ou não nas próprias notas musicais. Em seu artigo colocam a polêmica trazida pelo Jornal New York Times que, ao analisar gravações de compositoras lésbicas, "chega à conclusão que a preferência sexual, como o sexo, é inaudível”, chamando atenção de tal "conclusão ser inevitável”. Mas, os autores defendem que "as notas não se deixam tão facilmente separar de seu contexto (de execução, palco, gênero e audiência, bem como alusão musical): se despojadas de todas as associações - uma impossibilidade -, não podem gerar sentido" (BRETT e WOOD, 2002).

Esta é umas das questões que nos têm intrigado ao longo desta investigação. Até que ponto o fator gênero - e a orientação sexual, como nos estudos de Brett e Wood (op.cit.) - pode se expressar na produção musical de homens e mulheres. Ao tratar o tema a partir da análise de composições (partituras) a restrição torna-se ainda maior, visto que a "tradição musicológica esteve sempre muito mais voltada para análises formais do que para questões sensíveis às humanidades" (MELLO, 2006), como por exemplo, a performance, os espetáculos, as audiências, o contexto sócio-cultural, onde, sem dúvida, a questão de gênero desponta com muito mais evidência.

Ao questionar se há diferenças entre homens e mulheres na execução musical os relatos apontaram que é comum ouvir da audiência comparações neste sentido.

“a gente já escutou falar assim: - ah, pra mulher elas tocam bem”. ${ }^{25}$

"questão de técnica, isso aí, homem e mulher pode ter igual, [...] a única diferença que vai ter é a questão de agüentar um show por mais tempo, resistência por mais tempo, a força da batida, de agüentar a música inteira num pique maior". ${ }^{26}$

No hip-hop, a técnica não se apresentou com o mesmo grau de importância, sendo que a diferença principal entre mulheres e homens aparece no discurso presente nas letras das canções.

"A gente luta por nós mulheres, a gente mostra a realidade das mulheres [...] e essa realidade os rapazes não mostram. Nossas músicas giram em torno da causa feminina, sempre da causa feminina. Temos até um CD que fala de saúde, tudo da causa feminina, de aborto, sobre o corpo, tudo isso". ${ }^{27}$

Por outro lado, embora majoritariamente os relatos se encaminhem para uma minimização das diferenças entre os sexos, surge em determinado ponto uma certa desqualificação em relação à audiência feminina.

\footnotetext{
${ }^{25}$ Idem Nota 16.

${ }^{26}$ Idem Nota 16.

${ }^{27}$ Idem Nota 15.

DAPesquisa, Florianópolis, v.2, n.4, p. 500 - 510, 2007.
} 
"é muito mais fácil encontrar homem que esta na 'night' que sabe diferenciar a qualidade de um som bom do que uma mulher. Nesse meio do pagode é difícil ver uma mulher tocando, então é mais difícil ela entender". ${ }^{28}$

“as mulheres não tem muito interesse pela música, são poucas ainda. Há mais homens no mercado por que eles se interessam mais". ${ }^{29}$

Jacques (2007) também debate sobre a questão, referindo-se especificamente ao universo do rock, onde revela que alguns autores tendem a "relacionar as mulheres mais como fãs", sendo que a ligação delas "se dá mais pelo interesse pelos ídolos do que pela música” (op.cit. p.96).

\section{Considerações Finais}

Através dos relatos, observações e pesquisa em diferentes mídias, procuramos apontar para os diversos espaços que vêm sendo ocupados atualmente por grupos femininos na música popular brasileira; os diálogos que vêm sendo estabelecidos entre esses grupos e as organizações feministas; e de que forma a organização desses grupos musicais tem possibilitado a contestação e a transformação dos papéis de gênero vigentes.

Embora considerado um espaço masculino, percebemos ao longo do trabalho que a participação feminina no rock, abriu espaço para o surgimento de uma nova categoria - rock com vocal feminino -, bem como a promoção de eventos musicais específicos para elas, o que tem demonstrado que sua participação ao longo dos anos não as coloca como meras coadjuvantes, mas sim como condutoras de transformações significativas para este universo musical.

No hip-hop percebemos que as mulheres, em especial mulheres negras, estão encontrando um significativo espaço para fomentar discussões sobre as causas femininas, promovendo através das letras das canções a conscientização das mulheres sobre temas como aborto, cuidado com o corpo, uso de anticoncepcionais. Este também é um locus para a divulgação dos seus direitos civis, como por exemplo, licença maternidade, aposentadoria para donas de casa e domésticas, denúncia à violência contra mulheres, etc.

A crescente participação das mulheres no meio musical - seja como produtoras ou consumidoras - faz transparecer a necessidade de novos estudos e reflexões sobre o tema, que continua sendo pouco pesquisado, apesar da conquista de novos espaços e da crescente visibilidade de grupos femininos. No entanto, novos estudos demandam uma base teórica e o domínio de metodologias que ultrapassem o caráter descritivo e auxiliem na compreensão das especificidades que as relações de gênero vêm construindo no âmbito das manifestações artístico-musicais.

\footnotetext{
${ }^{28}$ Idem Nota 16.

${ }^{29}$ Thanira Rates, vocalista, ex-integrante da banda de rock Dorotéia vai à Praia.
} 


\section{Referências Bibliográficas}

BARBOSA, Maria José S. A Representação da Mulher nas Cantigas de Capoeira. Les femmes et la littérature. Special issue. Org. Carlos Maciel e Luiza Lobo. Journal of the Centre de Recherche sur les Identités Nationales et l'Interculturalité (CRINI) and the Département d'Études Lusophones de l'Université de Nantes, France. Forthcoming, 2005. Disponível em:

<http://www.plcs.umassd.edu/plcs12texts/barbosajun162006.doc>. Acessado em: 13/02/2007. BARBOSA, Viviane de Oliveira. Quebrando o Coco e Fazendo a Roça: Gênero e Identidade no Cotidiano de Quebradeiras de Coco Babaçu no Maranhão. 216p. $1^{\circ}$ Prêmio Construindo a Igualdade de Gênero - Redações e trabalhos científicos monográficos vencedores de 2005, Brasília: Secretaria Especial de Políticas para as Mulheres - Presidência da República, 2006, p.212-213.

BARONCELLI, N. C. da S. Mulheres Compositoras: elenco e repertório. Editora Roswitha Kempf, São Paulo, 1987.

BASTOS, Rafael de Menezes. A musicológica Kamayurá: para uma antropologia da comunicação no Alto Xingu. $2^{\text {a }}$ Ed. da UFSC, 1999.

BELTRÃO, Synval. A Musa-Mulher na Canção Brasileira. Ed. Liberdade, SP, 1993.

BRETT, Philip; WOOD, Elizabeth. Música lésbica e guei. Revista eletrônica de musicologia,

Curitiba, v. 7, Disponível em: <http://www.rem.ufpr.br /REMv7/Brett_Wood/Brett_e_Wood.html>, dezembro, 2002.

CHAVES, Adriana. Mulheres no Rock. Disponível em: <http://www.mulheresnorock.pop.com.br/textos/mnr3.htm>. Acessado em: 02/10/2006.

CITRON, Marcia J. Gender and the Musical Canon. Cambridge: University Press, 1993.

COSTA, Neusa Meirelles. A mulher na música popular brasileira. Disponível em:

<http://www.samba-choro.com.br/s-c/tribuna/samba-choro.0401/0405.html>. Acessado em: 02/10/2006.

CUSICK, Suzanne G. Feminist Theory, Music Theory, and the Mind/Body Problem. Perspectives of New Music, Vol 32, Number 1 (Winter 1994).

DINIZ, Edinha. Chiquinha Gonzaga: uma história de vida. Ed. Rosa dos Tempos, Rio de Janeiro, 1984.

ERTZOGUE, Marina Haizenreder. O canto das Quebradeiras: Cantigas de Trabalho das Mulheres Extrativistas de Coco na Região Bico do Papagaio. Revista Fragmento de Cultura, v. 12 n.6 p.11031110, Goiânia, nov/dez. 2002.

FARIA, Cleide Nogueira de. Puxando a Sanfona e Rasgando o Nordeste: Relações De Gênero Na Música Popular Nordestina (1950-1990). Revista Eletrônica de Humanidades, ISSN 1518-3394, v.3 - n.5, abr./maio de 2002.

HOLANDA, Joana C.; GERLING, Cristina Capparelli . Estudos de Gênero em Música a partir da Década de 90: Escopo e Abordagem. Revista Associação Nacional de Música, Revista ANM - Rio de Janeiro, v. XV, 2005.

HOLANDA, Joana C. Eunice Katunda (1915-1990) e Esther Scliar (1926-1978): Trajetórias individuais e análise de sonata para piano 'Sonata de Louvação' (1960) e 'Sonata para Piano' (1961). 2006. 172p. Tese (Doutorado) Programa de Pós-Graduação em Música. Universidade Federal do Rio Grande do Sul 2006.

JACQUES, Tatyana de Alencar. Comunidade Rock e bandas independentes de Florianópolis: uma etnografia sobre socialidade e concepções musicais. 2007. 142p. Dissertação (Mestrado) Programa de Pós-Graduação em Antropologia Social. Universidade Federal de Santa Catarina. 2007.

KATER, Carlos. Eunice Katunda, Musicista Brasileira. São Paulo: Annablume, 2001.

KRAMER, Lawrence. Music as Culural Practice, 1800-1900. California: University of California Press: 1990.

LIRA, Mariza. Chiquinha Gonzaga: grande compositora popular brasileira. 2. ed. Rio de Janeiro: Funarte, 1978.

DAPesquisa, Florianópolis, v.2, n.4, p. 500 - 510, 2007. 
MATOS, Maria Izilda S. Sensibilidades feminina: poética e música em Dolores Duran. Revista Labrys: estudos feministas n.5, Jan-Jul 2004.

MCCLARY, Susan. Feminine Endings. Minnesota: University of Minnesota Press, 1991.

MEDIA, Century. O rock de saias, quem diria? Virou coisa de mulher! Disponível em:

<http://www.mulheresnorock.pop.com.br/textos/mnr5.htm> Acessado em: 02/10/2006.

MELlO, Maria Ignez C. Música, Mito e Ritual entre os Wauja do Alto Xingu. 2005. 335p. Tese (Doutorado) Programa de Pós-Graduação em Antropologia Social. Universidade Federal de Santa Catarina. 2005.

Relações de Gênero e Musicologia: Reflexões para uma Análise do Contexto Brasileiro. In: SIMPÓSIO DE PESQUISA EM MÚSICA 3. Anais. DeArtes UFPR, Curitiba, 2006. p. 69-74.

PACHECO, Alberto J. V e KAYAMA, Adriana G. A cantora Lapinha e a presença musical feminina no Brasil colonial e imperial. In: SIMPÓSIO DE PESQUISA EM MÚSICA 3, Anais. DeArtes UFPR, Curitiba, 2006, p.7-12.

PIEDADE, Acácio Tadeu de C. O canto do Kawoká: música, cosmologia e filosofia entre os Wauja do Alto Xingu. 2004. 254p. Tese (Doutorado) Programa de Pós-Graduação em Antropologia Social. Universidade do Federal de Santa Catarina, 2004.

SANTA CRUZ, Maria Áurea. A Musa sem Máscara: a imagem da mulher na música popular brasileira. Editora Rosa dos Tempos, Rio de Janeiro, 1992.

SARTORI, Rafael. As mulheres e o rock ' $n$ ' roll. Disponível em:

<http://www.mulheresnorock.pop.com.br/textos/mnr6.htm> Acessado em: 02/10/2006.

SCARINCI, Silvana Ruffier. SAFO NOVELLA: a voz da poeta grega reapropriada por Bárbara Strozzi (Veneza, 1619 - 1677). In: SIMPÓSIO DE PESQUISA EM MÚSICA 3, Anais. DeArtes UFPR, Curitiba, 2006, p.13-20.

SILVA, Helena Lopes da. Música no Espaço Escolar e a Construção da Identidade de Gênero: um estudo de caso. 2000. 210p. Dissertação (Mestrado) Programa de Pós-Graduação em Música. Universidade Federal do Rio Grande do Sul. 2000.

SMALL, Cristopher. Musica, sociedad, educación. Madrid: Alianza, 1989.

STIVAL, Silvana Beeck. Chiquinha Gonzaga em Forrobodó. 2004. Dissertação (Mestrado) Programa de Pós-Graduação em Letras/Literatura Brasileira do Centro de Comunicação e Expressão. Universidade Federal de Santa Catarina. 2004.

VEIGA, Ana Maria. Mulheres em Rádio e Revista: Imagens Femininas na Época de Ouro da Música (Rio de Janeiro 1930/1945) 216p. $1^{\circ}$ Prêmio Construindo a Igualdade de Gênero Redações e trabalhos científicos monográficos vencedores, 2006, p.32-63.

WALSER, Robert. Running with the Devil: power, gender, and madness in heavy metal music. Middletown: Wesleyan University Press, 1993.

WELLER, Wivian. A presença feminina nas (sub)culturas juvenis: a arte de se tornar visível. Revista Estudos Feministas, Florianópolis, 13(1):216, jan-abr, 2005, p. 107-126.

WATERMAN, Ellen. Cassandra's Dream Song: A Literary Feminist Perspective. Perspectives of New Music, Vol 32, Number 2 (Summer 1994). 